\title{
(6) \\ Outcomes of ab interno trabeculectomy with the trabectome by degree of angle opening
} OPEN ACCESS

\author{
I I Bussel, ${ }^{1}$ K Kaplowitz, ${ }^{2}$ J S Schuman, ${ }^{1,3}$ N A Loewen, ${ }^{1}$ Trabectome Study Group
}

- Additional material is published online only. To view please visit the journal online (http://dx.doi.org/10.1136/ bjophthalmol-2014-305577).

${ }^{1}$ Department of Ophthalmology, UPMC Eye Center, Eye and Ear Institute, Ophthalmology and Visual Science Research Center, University of Pittsburgh School of Medicine, Pittsburgh, Pennsylvania, USA

${ }^{2}$ Department of Ophthalmology, Stony Brook University School of Medicine, Stony Brook, New York, USA

${ }^{3}$ Department of Bioengineering, Swanson School of Engineering, University of Pittsburgh, Pittsburgh, Pennsylvania, USA

\section{Correspondence to}

Dr Nils A Loewen, Department of Ophthalmology, UPMC Eye Center, Eye and Ear Institute, Ophthalmology and Visual Science Research Center, University of Pittsburgh School of Medicine, 203 Lothrop St, \#819, Pittsburgh, PA 15235 , USA;

loewen.nils@gmail.com

Received 22 May 2014 Revised 17 September 2014 Accepted 21 September 2014 Published Online First 21 October 2014

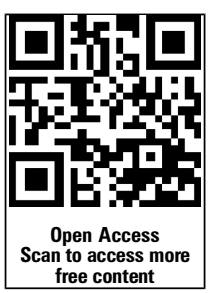

CrossMark

To cite: Bussel II, Kaplowitz K, Schuman JS, et al. Br J Ophthalmol 2015:99:914-919.

\section{ABSTRACT}

Aim To analyse ab interno trabeculectomy (AIT) with the trabectome and combined phacoemulsification with AIT (phaco-AIT) by Shaffer angle grade (SG).

Methods Prospective study of AIT and phaco-AIT with narrow angles of $S G \leq 2$ versus open angles $\geq 3$. Outcomes included intraocular pressure (IOP), medications, complications, secondary surgery and success (IOP $<21 \mathrm{~mm} \mathrm{Hg}$ and $>20 \%$ reduction without further surgery). Exclusion criteria were missing

preoperative data and $<1$ year follow-up.

Results Of 671 included cases, at 1 year AIT SG $\leq 2$ $(n=43)$ had an IOP reduction of $42 \%$ from $27.3 \pm 7.4$ to $15.7 \pm 3.0 \mathrm{~mm} \mathrm{Hg}(p<0.01)$ versus AIT SG $\geq 3 \quad(n=271)$ with an IOP reduction of $37 \%$ from $26.1 \pm 7.8$ to 16.4 $\pm 3.9 \mathrm{~mm} \mathrm{Hg}(p<0.01)$. In phaco-AlT with $\mathrm{SG} \leq 2 \quad(n=48)$, IOP was reduced $24 \%$ from $20.7 \pm 7.0$ to 15.7 $\pm 3.6 \mathrm{~mm} \mathrm{Hg}(p<0.01)$ versus phaco-AlT with $\mathrm{SG} \geq 3$ $(n=309)$ with an IOP reduction of $25 \%$ from $22.6 \pm 6.4$ to $17.0 \pm 3.4 \mathrm{~mm} \mathrm{Hg}(p<0.01)$. There was no difference between $S G \leq 2$ and $S G \geq 3$ in reduction of IOP or medications, complications, secondary surgery and success rates $(p>0.05)$.

Conclusions $S G \leq 2$ is not associated with worse outcomes in AlT or phaco-AIT.

\section{INTRODUCTION}

$\mathrm{Ab}$ interno trabeculectomy (AIT) with the trabectome (Neomedix Corporation, Tustin, California, USA) is a nearly 10 -year old, ${ }^{1}$ minimally invasive glaucoma surgery (MIGS) modality that lowers the intraocular pressure (IOP) by increasing aqueous outflow using plasma-mediated ablation of trabecular meshwork (TM). ${ }^{2}$ A narrow anterior chamber angle is considered a relative contraindication because surgeons feel that, in addition to an often less direct access during surgery, peripheral anterior synechiae, descemetisation of the angle and fibrosis may form more readily and hasten failure. ${ }^{3}$ This may preclude a large numbers of glaucoma patients from AIT and similar MIGS which have a highly favourable risk profile compared with traditional filtering glaucoma surgery with near absence of vision-threatening complications: while $74 \%$ of glaucomas present with an open angle, angleclosure glaucoma contributes up to $70 \%$ of glaucoma cases in women and to $87 \%$ of cases in Asians. ${ }^{4}$ Progressively narrow angles have been shown to be correlated with higher IOP, presumably by causing higher outflow resistance. ${ }^{5}$ Conversely, cataract surgery alone has been shown to deepen the angle and lower IOP. ${ }^{6}$

Although numerous studies have described the safety and efficacy of AIT in the treatment of glaucoma, ${ }^{17}$ the relationship between anterior chamber angle grade and outcomes has not been formally examined. The purpose of this nonrandomised study was to gain insight into whether the degree of preoperative angle opening relates to IOP outcomes of AIT or combined phacoemulsification with AIT (phaco-AIT), respectively. We hypothesised that narrow angles would be associated with worse IOP reduction and a higher failure rate.

\section{METHODS}

Subjects were enrolled from the Trabectome Study Group database, ${ }^{7}$ a postmarket surveillance requirement for Neomedix, and divided into phakic patients who had only trabectome-mediated AIT or combined phacoemulsification with AIT (phaco-AIT). Data for this study were collected with institutional review board approval, in accordance with the Declaration of Helsinki and the Health Insurance Portability and Accountability Act.

This prospective interventional cohort included all phakic patients with a diagnosis of glaucoma (with or without visually significant cataract), who had 12 months of follow-up. Anterior chamber angles in all patients were graded by Shaffer grade $(\mathrm{SG}){ }^{8}$ the most commonly used classification system in which ' 0 ' to 'slit' represents a totally or partially closed angle with potential for angle closure that is present or very likely, ' 1 ' an angle width of $10^{\circ}$ (very narrow) and closure potential that is probable, ' 2 ' representing $20^{\circ}$ and possible potential for closure, ' 3 ' standing for $20^{\circ}$ to $45^{\circ}$ with unlikely closure and grade ' 4 ' indicating a wide open angle and improbable potential for angle closure. Subjects were excluded if they had missing preoperative IOP data or end-stage visual field (VF) damage.

The indication for AIT alone in phakic eyes consisted of IOP above target with progressive glaucoma on maximally tolerated medical or laser therapy. All surgeons were recommended to follow the standard postoperative protocol consisting of $1 \%$ pilocarpine four times per day for 1 month then three times per day for 1 month, $1 \%$ prednisolone acetate four times per day for 1 week to be tapered by one drop each week and a fourth or third generation fluoroquinolone four times per day for 1 week. Glaucoma medications could be continued as deemed necessary to achieve target pressures. Deviations from this protocol were allowed at the clinician's discretion and not monitored.

We converted visual acuities to logarithm of the minimum angle of resolution (logMAR). The indication for phaco-AIT consisted of a visually significant cataract with at least 0.4 logMAR (20/50 Snellen) visual brightness acuity testing and the 
need to lower IOP or the number of glaucoma medications. VF status was categorised as early, moderate or advanced by individual glaucoma specialists based on the most recent Humphrey VF exams (Carl Zeiss Meditec AG, Jena, Germany). All patients had a comprehensive slit lamp and ophthalmoscopy exam prior to surgery.

The major outcome measures included IOP, number of glaucoma medications, and need for secondary glaucoma surgery. Each hypotensive agent in an eye drop was counted as a glaucoma medication. Pilocarpine and oral carbonic anhydrase inhibitors were also counted as a glaucoma medication. We used the Wilcoxon test to compare IOP and number of medications within each group and between groups, and the Mann-Whitney test and $\chi^{2}$ test to compare continuous and categorical variables between groups, respectively. All statistical analyses were performed using R. ${ }^{9}$ Statistical significance was set at $\mathrm{p}<0.05$. Continuous variables were expressed as mean \pm SD. We created scattergrams to illustrate individual outcomes and survival plots using a Kaplan-Meier survival analysis. Success was defined as a final IOP $<21 \mathrm{~mm} \mathrm{Hg}$ and a $>20 \%$ reduction from baseline without further surgery. We analysed survival rates by SGs with the log-rank test.

\section{RESULTS}

After applying exclusion criteria, a total of 671 eyes from 671 patients were included in this study (figure 1). In AIT, there were eight patients in SG1, 35 in SG2, 118 in SG3 and 153 in SG4. In phaco-AIT, there were six patients in SG1, 42 in SG2, 146 in SG3 and 163 in SG4. All patients were phakic and underwent AIT alone or phaco-AIT and had at least 12 months of follow-up. Baseline patient demographics are presented in table 1 . We estimated that the power to detect a difference of

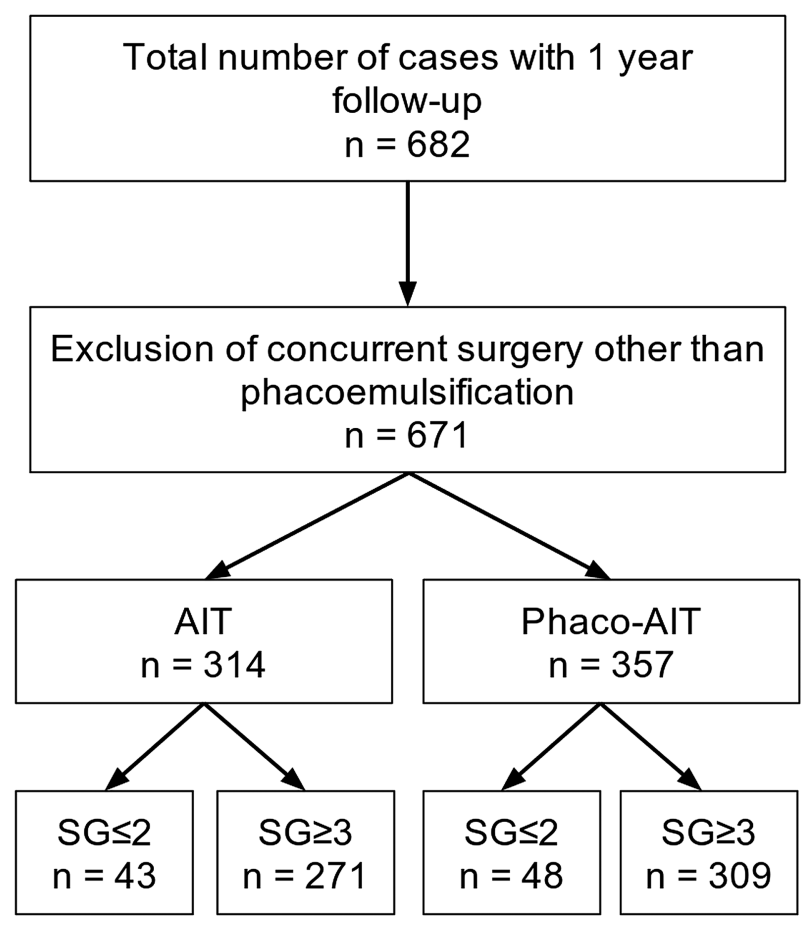

Figure 1 Trabectome Study Group Database. Cases analysed after accounting for exclusion criteria. AIT, ab interno trabeculectomy; phaco-AIT, phacoemulsification cataract surgery combined with ab interno trabeculectomy; SG, Shaffer grade.
$3 \mathrm{~mm} \mathrm{Hg}$ between groups was 97\% given the unequal sample sizes and the observed SD.

In the baseline patient demographics (table 1), the phaco-AIT group was on average about a decade older than the AIT group and the $S G \leq 2$ subgroup was older than $S G \geq 3$. Visual acuity in phaco-AIT improved significantly after surgery. AIT $S G \leq 2$ had proportionally more African-Americans, fewer Asians, and more subjects with a cup-to-disc ratio above 0.8 compared with AIT $S G \geq 3$. Additionally, the severity of VF damage was associated with SG groups primarily due to the substantial amount of advanced VF damage in $S G \geq 3$ that matched the greater number of cases with a cup-to-disc ratio above 0.8 .

Figures 2 and 3 show the preoperative and postoperative IOP measurements and change in glaucoma medications over time in AIT and phaco-AIT, respectively. In AIT $S G \leq 2$, the mean IOP was reduced from $27.3 \pm 7.4$ to $15.7 \pm 3.0 \mathrm{~mm} \mathrm{Hg} \quad(42 \%$ decrease, $\mathrm{p}<0.01)$, on 0.2 fewer medications $(\mathrm{p}=1.00)$ at 12 months. In AIT $S G \geq 3$, the mean IOP was reduced from 26.1 \pm 7.8 to $16.4 \pm 3.9 \mathrm{~mm} \mathrm{Hg}(37 \%$ decrease, $\mathrm{p}<0.01)$ on 0.8 fewer medications $(p<0.01)$. In phaco-AIT $S G \leq 2$, the mean IOP was reduced from $20.7 \pm 7.0$ to $15.7 \pm 3.6 \mathrm{~mm} \mathrm{Hg}(24 \%$ decrease, $\mathrm{p}<0.01)$, on 0.8 fewer medications $(\mathrm{p}<0.01)$. In phaco-AIT $S G \geq 3$, the mean IOP was reduced from $22.6 \pm 6.4$ to $17.0 \pm 3.4 \mathrm{~mm} \mathrm{Hg}(25 \%$ decrease, $\mathrm{p}<0.01)$ on 0.7 fewer medications $(p<0.01)$. Online supplementary table $S 1$ details how many patients in each study group were using $0,1,2,3$ or 4 medications at each time point.

Table 2 indicates similar surgical success in AIT and phaco-AIT by SG using various criteria. The scattergrams in figure 4 plotted the 1 and 12 month IOP against the baseline IOPs of each group. A few higher IOPs were recorded in select individuals at 1 month compared with 12 months. No significant differences were found between any single group or between all AITs (SG $\leq 2$ plus $S G \geq 3)$ compared with all phaco-AIT ( $\mathrm{SG} \leq 2$ plus $\mathrm{SG} \geq 3 ; \mathrm{p}>0.05$ ). Figure 5 shows comparable survival plots with no significant difference between $S G \leq 2$ and $S G \geq 3$ groups for neither AIT $(p=0.70)$ nor phaco-AIT $(p=0.56)$ although the survival curve for $S G \geq 3$ both AIT and phaco-AIT was slightly above those for $S G \leq 2$.

Table 3 presents postoperative complications. A total of 63 AIT and 11 phaco-AIT cases went on to require further glaucoma surgery within 12 months. There was no statistical difference in secondary surgery events when compared by SG. There were five cases of transient hypotony in both the AIT and phaco-AIT $S G \geq 3$ groups, but the hypotony spontaneously resolved and there was no vision loss. There were no serious complications that are commonly seen in trabeculectomy or tube shunt surgery including aqueous misdirection, infection, wound leaks, choroidal effusions or choroidal haemorrhage. IOP elevation of $>10 \mathrm{~mm} \mathrm{Hg}$ was not common (table 3 ) and few individuals had high pressures (figure 4).

\section{DISCUSSION}

In this study, we evaluated the outcomes of AIT and phaco-AIT by degree of angle opening. No statistically significant differences between narrow $(S G \leq 2)$ and open $(S G \geq 3)$ angles were found in IOP and number of medications at 12 months. Narrow angles have previously been seen as a relative contraindication to AIT, whereas phaco-AIT has been performed in narrow angles with less concern because removal of the crystalline lens deepens the anterior chamber angle and may resolve angle closure. ${ }^{10-12}$ Patients in phaco-AIT were on average about a decade older than in AIT and patients in subgroup $S G \leq 2$ were older than ones in $S G \geq 3$. Visual acuity was worse in AIT $S G \leq 2$ 
Table 1 Baseline patient demographics

\begin{tabular}{|c|c|c|c|c|c|c|}
\hline & AIT & $n=314$ & & Phaco-AlT & $n=357$ & \\
\hline & $\begin{array}{l}S G \leq 2 \\
(n=43)\end{array}$ & $\begin{array}{l}S G \geq 3 \\
(n=271)\end{array}$ & p Value & $\begin{array}{l}S G \leq 2 \\
(n=48)\end{array}$ & $\begin{array}{l}S G \geq 3 \\
(n=309)\end{array}$ & p Value \\
\hline Age (years) & & & $<0.01$ * & & & 0.10 \\
\hline Mean \pm SD & $68 \pm 11$ & $61 \pm 14$ & & $76 \pm 8$ & $73 \pm 10$ & \\
\hline Range & 39-87 & $18-91$ & & 54-93 & 27-91 & \\
\hline Gender & & & 0.47 & & & 0.73 \\
\hline Female & $24(56 \%)$ & $128(47 \%)$ & & $27(56 \%)$ & $179(58 \%)$ & \\
\hline Male & $19(44 \%)$ & $140(52 \%)$ & & $21(44 \%)$ & $125(40 \%)$ & \\
\hline NR & $0(0 \%)$ & $3(1 \%)$ & & $0(0 \%)$ & $5(2 \%)$ & \\
\hline Ethnicity & & & $<0.01$ & & & 0.64 \\
\hline African-American & $8(19 \%)$ & $19(7 \%)$ & & $3(6 \%)$ & $21(7 \%)$ & \\
\hline Asian & $2(4 \%)$ & $53(19 \%)$ & & $18(38 \%)$ & $94(30 \%)$ & \\
\hline Caucasian & $28(65 \%)$ & $136(50 \%)$ & & $21(44 \%)$ & $169(55 \%)$ & \\
\hline Hispanics & $5(12 \%)$ & $47(17 \%)$ & & $2(4 \%)$ & $10(3 \%)$ & \\
\hline Other & $0(0 \%)$ & $16(6 \%)$ & & $4(8 \%)$ & $15(5 \%)$ & \\
\hline Glaucoma & & & 0.47 & & & $<0.01$ \\
\hline Primary open angle & $34(79 \%)$ & $195(72 \%)$ & & $31(65 \%)$ & $240(78 \%)$ & \\
\hline Pseudoexfoliation & $5(11 \%)$ & $30(11 \%)$ & & $5(10 \%)$ & $39(13 \%)$ & \\
\hline Secondary open angle & $2(5 \%)$ & $36(13 \%)$ & & $5(10 \%)$ & $19(6 \%)$ & \\
\hline Others & $2(5 \%)$ & $10(4 \%)$ & & $7(15 \%)$ & $11(4 \%)$ & \\
\hline Acuity (logMAR) & & & 0.67 & & & 0.60 \\
\hline Preop & $0.47 \pm 0.85$ & $0.37 \pm 0.56$ & & $0.48 \pm 0.42$ & $0.47 \pm 0.45$ & \\
\hline Postop & $0.30 \pm 0.63$ & $0.32 \pm 056$ & & $0.29 \pm 0.59$ & $0.20 \pm 0.31$ & \\
\hline Change $p$ value & $p=0.76$ & $p=0.50$ & & $p<0.01$ & $p<0.01$ & \\
\hline VF & & & 0.95 & & & 0.02 \\
\hline Mild & $13(30 \%)$ & $89(33 \%)$ & & $13(27 \%)$ & $75(24 \%)$ & \\
\hline Moderate & $17(40 \%)$ & $93(34 \%)$ & & $14(29 \%)$ & $92(30 \%)$ & \\
\hline Advanced & $10(23 \%)$ & $70(26 \%)$ & & $8(17 \%)$ & $104(34 \%)$ & \\
\hline MD/other & $3(7 \%)$ & $19(7 \%)$ & & $13(27 \%)$ & $38(12 \%)$ & \\
\hline Disc C/D & & & 0.03 & & & 0.29 \\
\hline$<0.7$ & $12(28 \%)$ & $65(24 \%)$ & & $16(33 \%)$ & $67(22 \%)$ & \\
\hline $0.7-0.8$ & $12(28 \%)$ & 112 (41\%) & & $19(40 \%)$ & $125(40 \%)$ & \\
\hline$>0.8$ & $19(44 \%)$ & $73(27 \%)$ & & $10(21 \%)$ & $87(28 \%)$ & \\
\hline NR & $0(0 \%)$ & $21(8 \%)$ & & $3(6 \%)$ & $30(10 \%)$ & \\
\hline
\end{tabular}

AIT, ab interno trabeculectomy; SG, Shaffer grade; VF, visual field.

compared with $S G \geq 3$, reflecting the average age at which cataracts become visually significant. ${ }^{13}{ }^{14}$ Lens thickness increases with age ${ }^{15}$ and can lead to a diminished anterior chamber depth $^{16}$ and even to phacomorphic angle closure in predisposed individuals. ${ }^{17-19}$

We observed a mean IOP decrease by approximately $40 \%$ from about $27 \mathrm{~mm} \mathrm{Hg}$ in the AIT groups and by approximately $24 \%$ from about $21 \mathrm{~mm} \mathrm{Hg}$ in the phaco-AIT groups. These findings are similar to previous results that reported a higher baseline IOP in the AIT group and are reflective of different indications ${ }^{1} 720$ that consisted of high IOP in AIT and of a visually significant cataract and also high IOP or desire to reduce dependence on glaucoma medications in phaco-AIT. Twelve-month pressures and medication reduction were not significantly different, suggesting that AIT-mediated IOP reduction cannot be predicted as a fraction of preoperative levels and that outflow resistance downstream of the TM was similar in all eyes and additive to episcleral venous pressure. ${ }^{21} 22$

Phacoemulsification in itself has been noted to decrease IOP by $1.5-3 \mathrm{~mm} \mathrm{Hg},{ }^{23-25}$ possibly via decompression or mechanical stretch of the TM and Schlemm's canal ${ }^{26}$ or a stress response pathway activated by ultrasound and other surgical factors. ${ }^{27}$ However, after TM ablation, one would not expect an additional IOP reduction via these mechanisms. This argues

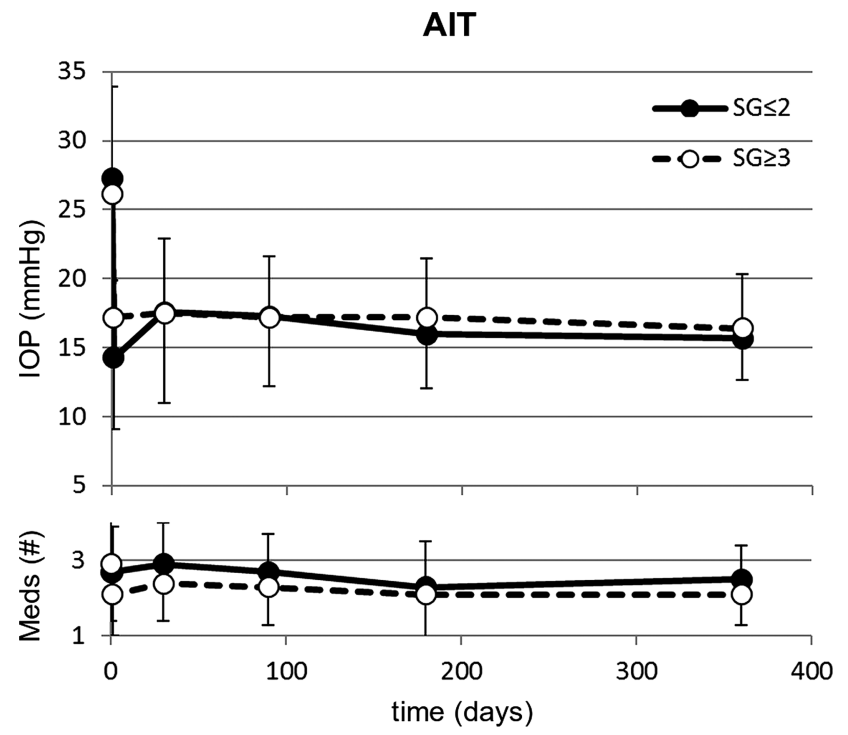

Figure 2 In AIT, no significant differences were found in IOP and glaucoma medications use between in patients with a narrow $(\mathrm{SG} \leq 2, \mathrm{n}=43$ ) and a deep anterior chamber angle ( $\mathrm{SG} \geq 3, \mathrm{n}=271)$ over a 1 year period. AIT, ab interno trabeculectomy; IOP, intraocular pressure; SG, Shaffer grade. 
phaco-AIT

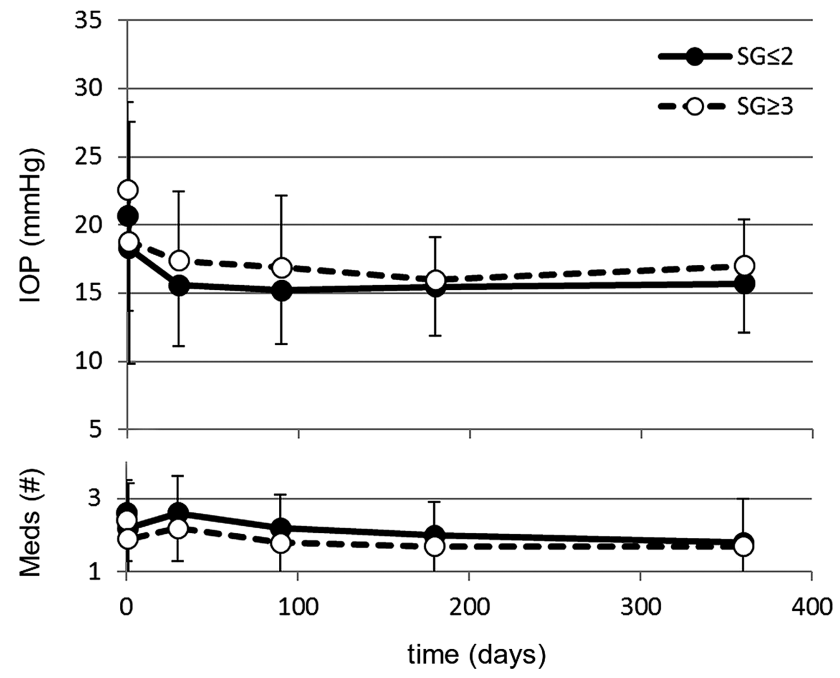

Figure 3 In phaco-AIT, no significant differences were found in IOP and glaucoma medications use between in patients with a narrow $(\mathrm{SG} \leq 2, \mathrm{n}=48)$ and a deep anterior chamber angle $(S G \geq 3, n=309)$ over a 1 year period. AIT, ab interno trabeculectomy; IOP, intraocular pressure; SG, Shaffer grade.

against cataract surgery significantly contributing to outcomes in phaco-AIT in contrast to other MIGS modalities where phacoemulsification alone was found to be nearly as effective as the combination under study. ${ }^{28}$

The relative efficacy and safety of AIT is apparent by the individual outcomes data in the scattergrams (figure 4): both AIT and phaco-AIT contain subjects with very high preoperative IOP yet no patient had sustained hypotony or other serious postoperative complications (table 3). Few patients experienced a postoperative IOP elevation as seen in other glaucoma surgeries. $^{29}$ This was more common in phaco-AIT where viscoelastic was used for lens injection. Our study of AIT and phaco-AIT in
Table 2 Success table at 12 months for AIT and phaco-AIT

\begin{tabular}{lcc}
\hline & SG $\leq 2(\mathrm{n}=43)$ & SG $\geq 3(\mathbf{n}=\mathbf{2 7 1})$ \\
\hline AIT & & \\
$\leq 21 \mathrm{~mm} \mathrm{Hg}$ or $20 \%$ Reduction & $32(74 \%)$ & $206(76 \%)$ \\
$\leq 21 \mathrm{~mm} \mathrm{Hg}$ and $20 \%$ Reduction & $29(67 \%)$ & $157(58 \%)$ \\
$\leq 18 \mathrm{~mm} \mathrm{Hg}$ or $20 \%$ Reduction & $31(72 \%)$ & $195(72 \%)$ \\
$\leq 18 \mathrm{~mm} \mathrm{Hg}$ and $20 \%$ Reduction & $22(51 \%)$ & $118(44 \%)$ \\
$\leq 15 \mathrm{~mm} \mathrm{Hg}$ or $20 \%$ Reduction & $31(72 \%)$ & $175(65 \%)$ \\
$\leq 15 \mathrm{~mm} \mathrm{Hg}$ and $20 \%$ Reduction & $13(30 \%)$ & $67(25 \%)$ \\
$\leq 12 \mathrm{~mm} \mathrm{Hg}$ or $20 \%$ Reduction & $30(70 \%)$ & $167(62 \%)$ \\
$\leq 12 \mathrm{~mm} \mathrm{Hg}$ and 20\% Reduction & $3(7 \%)$ & $16(6 \%)$ \\
& $\mathrm{SG} \leq 2(\mathrm{n}=48)$ & $\mathrm{SG} \geq 3(\mathrm{n}=309)$ \\
Phaco-AIT & & \\
$\leq 21$ or $20 \%$ Reduction & $44(92 \%)$ & $282(91 \%)$ \\
$\leq 21$ and $20 \%$ Reduction & $27(56 \%)$ & $158(51 \%)$ \\
$\leq 18$ or $20 \%$ Reduction & $39(81 \%)$ & $258(83 \%)$ \\
$\leq 18$ and $20 \%$ Reduction & $17(35 \%)$ & $128(41 \%)$ \\
$\leq 15$ or $20 \%$ Reduction & $35(73 \%)$ & $216(70 \%)$ \\
$\leq 15$ and $20 \%$ Reduction & $7(15 \%)$ & $80(26 \%)$ \\
$\leq 12$ or $20 \%$ Reduction & $29(60 \%)$ & $170(55 \%)$ \\
$\leq 12$ and $20 \%$ Reduction & $2(4 \%)$ & $24(8 \%)$ \\
\hline AIT, ab interno trabeculectomy; SG, Shaffer grade. &
\end{tabular}

glaucoma with narrow angles is not directly comparable with studies of trabeculectomy or tube shunt surgery in chronic angle-closure glaucoma (CACG), in which patients had angle closure of at least $180^{\circ}$ and synechiae. ${ }^{30-32}$ Sihota et al described an unusually good success rate above $90 \%$ using trabeculectomy and glaucoma drops to achieve an IOP below $21 \mathrm{~mm} \mathrm{Hg}$. The rate of complications was high with flat chambers occurring in 40\% and decreased vision in 58\%. Another trial found that phacotrabeculectomy lowered the IOP only by an additional $1.8 \mathrm{~mm} \mathrm{Hg}$ compared with phacoemulsification alone and achieved this with 1.2 fewer medications. ${ }^{30}$ Tube shunts are used less commonly in angle-closure glaucomas
1 Month
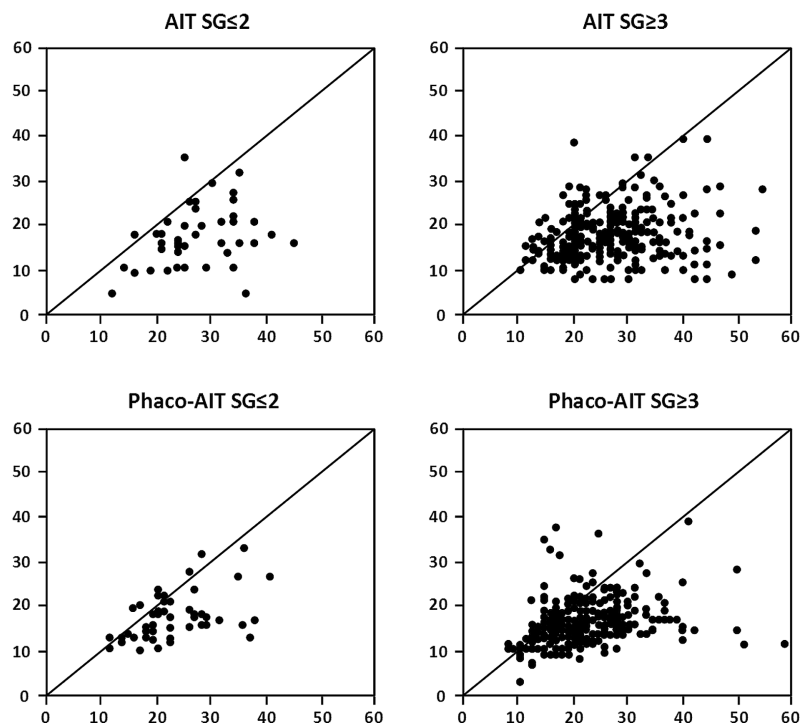
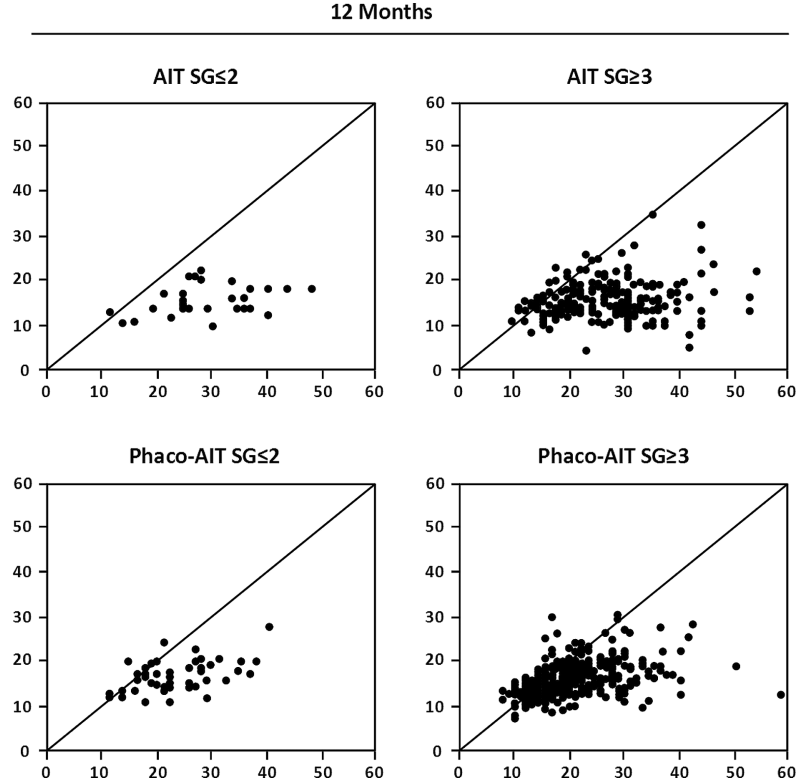

Figure 4 Scattergrams for AIT (top) and phaco-AIT (bottom) demonstrating IOP change from preoperative baseline to final measurement at 1 month (left) and at 12 months (right). There were no significant differences between single groups or between all AIT compared with all phaco-AIT $(p>0.05)$. AIT, ab interno trabeculectomy; IOP, intraocular pressure. 
Figure 5 Kaplan-Meier survival plots for AIT (left) and phaco-AIT (right) with success defined as a final IOP of $<21 \mathrm{~mm} \mathrm{Hg}$ and a $>20 \%$ reduction from baseline without further surgery. No statistically significant difference between SG groups in AIT ( $p=0.70)$ and phaco-AIT $(p=0.56)$. AIT, ab interno trabeculectomy; IOP, intraocular pressure; SG, Shaffer grade.
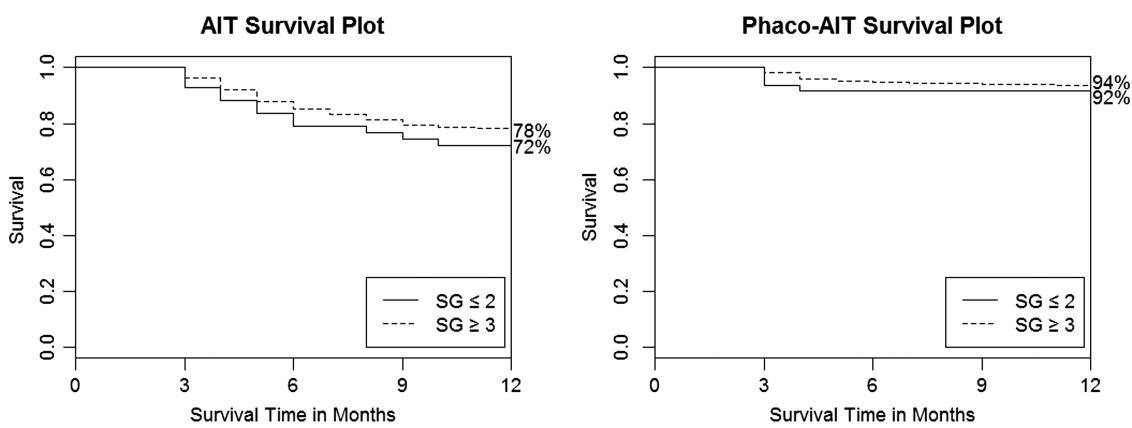

Table 3 Postoperative complications in AIT and phaco-AIT

\begin{tabular}{|c|c|c|c|c|c|c|}
\hline & \multicolumn{3}{|l|}{ AIT } & \multicolumn{3}{|c|}{ Phaco-AIT } \\
\hline & $\begin{array}{l}S G \leq 2 \\
(n=43)\end{array}$ & $\begin{array}{l}S G \geq 3 \\
(n=271)\end{array}$ & $p$ Value & $\begin{array}{l}S G \leq 2 \\
(n=48)\end{array}$ & $\begin{array}{l}S G \geq 3 \\
(n=309)\end{array}$ & p Value \\
\hline Total secondary surgery & $11(26 \%)$ & $52(19 \%)$ & 0.44 & $2(4 \%)$ & $9(3 \%)$ & 0.99 \\
\hline \multicolumn{7}{|l|}{ Hypotony $(\mathrm{IOP}<5 \mathrm{~mm} \mathrm{Hg}$ ) } \\
\hline Day 1 & $0(0 \%)$ & $5(2 \%)$ & 0.61 & $0(0 \%)$ & $5(2 \%)$ & 0.82 \\
\hline Week 1-month 3 & $0(0 \%)$ & $0(0 \%)$ & & $0(0 \%)$ & $0(0 \%)$ & \\
\hline \multicolumn{7}{|l|}{ IOP elevation $>10 \mathrm{~mm} \mathrm{Hg}$} \\
\hline Day 1 & $0(0 \%)$ & $14(5 \%)$ & 0.23 & $4(8 \%)$ & $25(8 \%)$ & 1.00 \\
\hline Week 1-month 3 & $0(0 \%)$ & $1(0.4 \%)$ & 1.00 & $2(4 \%)$ & $14(5 \%)$ & 1.00 \\
\hline Aqueous misdirection & $0(0 \%)$ & $0(0 \%)$ & & $0(0 \%)$ & $0(0 \%)$ & \\
\hline Infection & $0(0 \%)$ & $0(0 \%)$ & & $0(0 \%)$ & $0(0 \%)$ & \\
\hline Bleb formation & $0(0 \%)$ & $0(0 \%)$ & & $0(0 \%)$ & $0(0 \%)$ & \\
\hline Wound leaks & $0(0 \%)$ & $0(0 \%)$ & & $0(0 \%)$ & $0(0 \%)$ & \\
\hline Problematic pain & $0(0 \%)$ & $0(0 \%)$ & & $0(0 \%)$ & $0(0 \%)$ & \\
\hline Choroidal effusion & $0(0 \%)$ & $0(0 \%)$ & & $0(0 \%)$ & $0(0 \%)$ & \\
\hline Choroidal haemorrhage & $0(0 \%)$ & $0(0 \%)$ & & $0(0 \%)$ & $0(0 \%)$ & \\
\hline
\end{tabular}

AIT, ab interno trabeculectomy; IOP, intraocular pressure; SG, Shaffer grade.

without same session lens extraction because of challenges in fitting the shunt into the anterior chamber. Wilson et $a l^{33}$ reported on 46 primary open angle glaucoma and 13 CACG eyes and found that while on average more than one complication occurred per eye, surgical success was nevertheless achieved in $68 \%$ of cases.

Our study suggests that AIT can be considered in the relatively large population of patients with narrow angles. It was limited by sample size differences and only 1-year follow-up. The results will enable informed design of randomised controlled trials to analyse outcomes and angle changes after AIT in glaucoma patients regardless of angle degree.

In conclusion, AIT and phaco-AIT significantly reduced IOP and number of medications regardless of degree of angle opening and indications should be expanded to include narrow angles.

Acknowledgements We would like to acknowledge Ms Jane Lin for her technical support.

Contributors IIB: data collection, statistics, manuscript writing and review, and surgical assistance. KK: statistics, manuscript writing and review, and surgery. JSS: manuscript review and surgery. NAL: data collection, statistics, manuscript writing and review, and surgery.

Competing interests NAL has served as a trabectome wet lab trainer for Neomedix.

Ethics approval Institutional Review Board.

Provenance and peer review Not commissioned; externally peer reviewed.
Data sharing statement All data collected here are contained within the manuscript.

Open Access This is an Open Access article distributed in accordance with the Creative Commons Attribution Non Commercial (CC BY-NC 4.0) license, which permits others to distribute, remix, adapt, build upon this work non-commercially, and license their derivative works on different terms, provided the original work is properly cited and the use is non-commercial. See: http://creativecommons.org/ licenses/by-nc/4.0/

\section{REFERENCES}

1 Minckler DS, Baerveldt G, Alfaro MR, et al. Clinical results with the Trabectome for treatment of open-angle glaucoma. Ophthalmology 2005;112:962-7.

2 Kaplowitz K, Schuman JS, Loewen NA. Techniques and outcomes of minimally invasive trabecular ablation and bypass surgery. Br J Ophthalmol 2014;98: 579-85.

3 Liu J, Jung J, Francis BA. Ab interno trabeculotomy: Trabectome ${ }^{\mathrm{TM}}$ surgical treatment for open-angle glaucoma. Expert Rev Ophthalmol 2009;4:119-28.

4 Quigley HA, Broman AT. The number of people with glaucoma worldwide in 2010 and 2020. Br J Ophthalmol 2006;90:262-7.

5 Bhargava SK, Leighton DA, Phillips Cl. Early angle-closure glaucoma. Distribution of iridotrabecular contact and response to pilocarpine. Arch Ophthalmol 1973;89: 369-72.

6 Hayashi K, Hayashi H, Nakao F, et al. Changes in anterior chamber angle width and depth after intraocular lens implantation in eyes with glaucoma. Ophthalmology 2000;107:698-703.

7 Minckler D, Mosaed S, Dustin L. Trabectome (trabeculectomy-internal approach): additional experience and extended follow-up. Trans Am Ophthalmol Soc 2008;106:149-59; discussion 159-60.

8 Stamper RL. CHAPTER 7-Clinical interpretation of gonioscopic findings. In: Stamper RL, Lieberman MF, Drake MV. eds. Becker-Shaffer's Diagnosis and Therapy of the Glaucomas. 8th edn. Mosby, 2009:78-90. 
9 R Core Team. R: A Language and Environment for Statistical Computing. Vienna, Austria. R Foundation for Statistical Computing, 2014. http://www.R-project.org/

10 Barbosa DTQ, Levison AL, Lin SC. Clear lens extraction in angle-closure glaucoma patients. Int J Ophthalmol 2013;6:406-8.

11 Shin HC, Subrayan V, Tajunisah I. Changes in anterior chamber depth and intraocular pressure after phacoemulsification in eyes with occludable angles. J Cataract Refract Surg 2010;36:1289-95.

12 Nonaka A, Kondo T, Kikuchi M, et al. Angle widening and alteration of ciliary process configuration after cataract surgery for primary angle closure. Ophthalmology 2006;113:437-41.

13 Klein BE, Klein R, Lee KE. Incidence of age-related cataract: the Beaver Dam Eye Study. Arch Ophthalmol 1998;116:219-25.

14 Leske MC, Wu SY, Nemesure B, et al. Incidence and progression of lens opacities in the Barbados Eye Studies. Ophthalmology 2000;107:1267-73.

15 Hashemi $H$, Khabazkhoob M, Miraftab M, et al. The distribution of axial length, anterior chamber depth, lens thickness, and vitreous chamber depth in an adult population of Shahrud, Iran. BMC Ophthalmol 2012;12:50.

16 Salmon JF. Presenting features of primary angle-closure glaucoma in patients of mixed ethnic background. S Afr Med J 1993;83:594-7.

17 Kothari R, Tathe S, Gogri P, et al. Lens-induced glaucoma: the need to spread awareness about early management of cataract among rural population. ISRN Ophthalmol 2013;2013:581727.

18 Lee JWY, Lai JSM, Yick DWF, et al. Retrospective case series on the long-term visual and intraocular pressure outcomes of phacomorphic glaucoma. Eye 2010;24:1675-80.

19 Leung CKS, Chan W-M, Ko CY, et al. Visualization of anterior chamber angle dynamics using optical coherence tomography. Ophthalmology 2005;112:980-4.

20 Francis BA, Minckler D, Dustin L, et al. Combined cataract extraction and trabeculotomy by the internal approach for coexisting cataract and open-angle glaucoma: initial results. J Cataract Refract Surg 2008;34:1096-103.

21 Nau CB, Malihi M, McLaren JW, et al. Circadian variation of aqueous humor dynamics in older healthy adults. Invest Ophthalmol Vis Sci 2013;54:7623-9.

22 Fellman RL, Grover DS. Episcleral venous fluid wave: intraoperative evidence for patency of the conventional outflow system. J Glaucoma 2014;23:347-50.
23 Mansberger SL, Gordon MO, Jampel H, et al. Reduction in intraocular pressure after cataract extraction: the Ocular Hypertension Treatment Study. Ophthalmology 2012;119:1826-31.

24 Yang HS, Lee J, Choi S. Ocular biometric parameters associated with intraocular pressure reduction after cataract surgery in normal eyes. Am J Ophthalmol 2013;156:89-94.e1.

25 Shingleton BJ, Pasternack JJ, Hung JW, et al. Three and five year changes in intraocular pressures after clear corneal phacoemulsification in open angle glaucoma patients, glaucoma suspects, and normal patients. J Glaucoma 2006;15:494-8.

26 Poley BJ, Lindstrom RL, Samuelson TW, et al. Intraocular pressure reduction after phacoemulsification with intraocular lens implantation in glaucomatous and nonglaucomatous eyes: evaluation of a causal relationship between the natural lens and open-angle glaucoma. J Cataract Refract Surg 2009;35:1946-55. http://www. sciencedirect.com/science/article/pii/S0886335009007664

27 Wang N, Chintala SK, Fini ME, et al. Ultrasound activates the TM ELAM-1/IL-1/ NF-kappaB response: a potential mechanism for intraocular pressure reduction after phacoemulsification. Invest Ophthalmol Vis Sci 2003;44:1977-81.

28 Samuelson TW, Katz LJ, Wells JM, et al. Randomized evaluation of the trabecular micro-bypass stent with phacoemulsification in patients with glaucoma and cataract. Ophthalmology 2011;118:459-67.

29 Gedde SJ, Herndon LW, Brandt JD, et al. Surgical complications in the Tube Versus Trabeculectomy Study during the first year of follow-up. Am J Ophthalmol 2007;143:23-31.

30 Tham CCY, Leung DYL, Kwong YYY, et al. Effects of phacoemulsification versus combined phaco-trabeculectomy on drainage angle status in primary angle closure glaucoma (PACG). J Glaucoma 2010;19:119-23.

31 Sihota R, Gupta V, Agarwal HC. Long-term evaluation of trabeculectomy in primary open angle glaucoma and chronic primary angle closure glaucoma in an Asian population. Clin Experiment Ophthalmol 2004;32:23-8.

32 Alsagoff $Z$, Aung $T$, Ang LP, et al. Long-term clinical course of primary angle-closure glaucoma in an Asian population. Ophthalmology 2000;107:2300-4.

33 Wilson MR, Mendis U, Paliwal A, et al. Long-term follow-up of primary glaucoma surgery with Ahmed glaucoma valve implant versus trabeculectomy. Am J Ophthalmol 2003;136:464-70. 